\title{
Design and Fabrication of Four Wheel Steering Mechanism for Low Speeds
}

\author{
K J Yogesh ${ }^{1}$, Mohd Rehan Desai ${ }^{2}$, Mohammed Ali Fazal Shaikh ${ }^{3}$, Praveen Gasthi ${ }^{4}$ \\ Department of Mechanical Engineering, Jain College of Engineering, Belagavi, Karnataka, India ${ }^{1,2,3,4}$
}

\begin{abstract}
This paper comprises of the Design \& Fabrication of a Four Wheel Steering mechanism which relatively is a new technology that improves manoeuvrability in trucks, cars, trailers \& other four wheelers. In general two wheel steering vehicles, the rear wheels do not play any role in association with the steering, i.e they follow the path of the front wheels. In a four wheel system the rear wheels are made to turn left \& right as per the requirements. To keep the operation as simple as possible a computer controlled mechanism can be incorporated for the rear wheels. The rear wheels can be controlled in the following fundamental ways: At slow speeds the rear wheels turn in the opposite direction of the front wheels. This can reduce the turning radius approximately by $21 \%$. At faster speeds on the highway, the rear wheels are made to turn in the same direction of the front wheels. This improves the lane changing manoeuvrability \& is particularly beneficial for vehicle towing. Out of the various possible mechanisms, Rack \& Pinion type is being presented in this paper.
\end{abstract}

Index Terms: Four Wheel Steer, Quadra-steer, Steering Mechanisms, Turning Radius Reduction.

\section{INTRODUCTION}

Nowadays, the problem of increased road traffic has made the handling of vehicles even difficult. Thereby there is a need to find an alternative mechanism for easy steering (turning) of the vehicles. At times when a vehicle is in a congested or a narrow area everyone would want to have a better turning response from the vehicle or want the vehicle to move sidewards without much or without any forward movement. Here comes the application of a Four wheel steered vehicle.It should not be mistaken to a four wheel drive in which all four wheels of a vehicle are powered. Here, the rear wheels are also bought into action as they are made to engage their movement in accordance to the front wheels in the directions required. This makes the vehicle be more precisely controlled especially during cornering, parking, or when we get into a narrow area. The main ideology behind this mechanism is that the vehicle requires less driver input for any steering maneuver when all four wheels are in action. The entire vehicle is made to move in a direction rather than the rear wheels half attempting to catch $\mathrm{u}$ with the front ones. The vehicle is made to respond even quicker to the steering input as the lag time of the rear wheel is eliminated here. However, few cars like Honda Prelude, Nissan Skyline GT-R are available with four wheel steering having their rear wheels steered up to 2 to 3 degrees only as their main aim was to assist the front wheels.

\section{LITERATURE REVIEW}

These steering systems of the present generation focuses on the need of steering of rear wheels for the reason of stability in direction.

\section{- Condition for True Rolling}

While tackling a turn, the condition of perfect rolling motion will be satisfied if all the four wheel axes when projected at one point called the instantaneous centre, and when the following equation is satisfied,

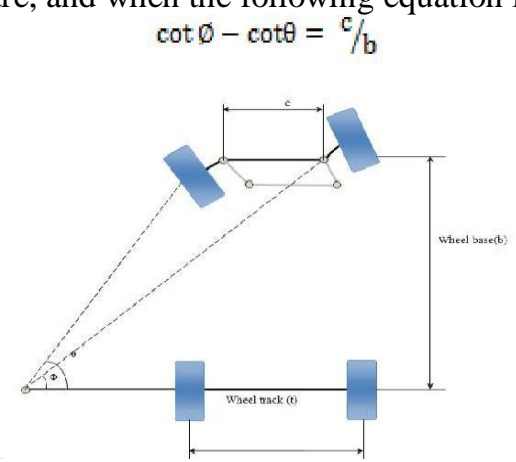

Fig 1: True Rolling Condition 


\section{- Slow and High Speed Modes}

At Slow Speeds rear wheels turn in direction opposite to that of front wheels. This mode is used for navigating through hilly areas and in congested city where better cornering is required for $\mathrm{U}$ turn and tight streets with low turning circle which can be reduced as shown in Fig 2.

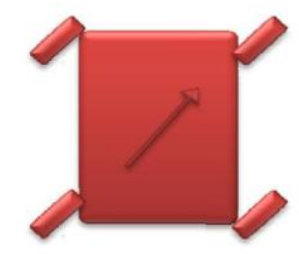

Fig 2: Slow Speed

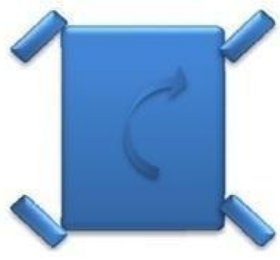

High Speed

At High Speed, turning the rear wheels through an angle opposite to front wheels might lead to vehicle instability and is thus unsuitable. hence the rear wheels are turned in the same direction of front wheels in four wheels in four wheel steering system.

\section{- $\quad$ Parallel Parking}

Zero steer can significantly ease the parking process, due to its extremely short turning footprint. This is exemplified by the parallel parking scenario, which is common in foreign countries and is pretty relevant to our cities. Here, a car has to park it between two other cars parked on the service lane. This maneuver requires a three-way movement of the vehicle and consequently heavy steering inputs. Moreover, to successfully park the vehicle without incurring any damage, at least 1.75 times the length of the car must be available for parking for a two-wheel steered car

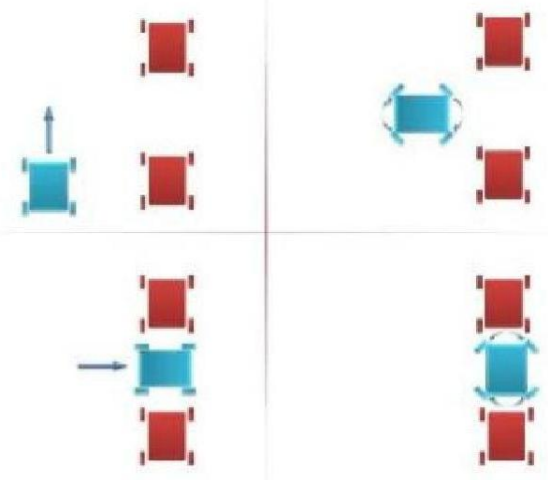

Fig 3: Parallel Parking

As can be seen clearly, the car requires just about the same length as itself to park in the spot. Also, since the 360 mode does not require steering inputs, the driver can virtually park the vehicle without even touching the steering wheel. All he has to do give throttle and brake inputs, and even they can be automated in modern cars. Hence, such a system can even lead to vehicles that can drive and park by themselves.

\section{- $\quad$ High Speed Lane Changing}

Another driving maneuver that frequently becomes cumbersome and even dangerous is changing lanes at fairly high speeds. Although this is less steering intensive, this does not require a lot concentration from the driver since he has to judge the space and vehicles behind him. Here is how crab mode can simplify this action as shown.

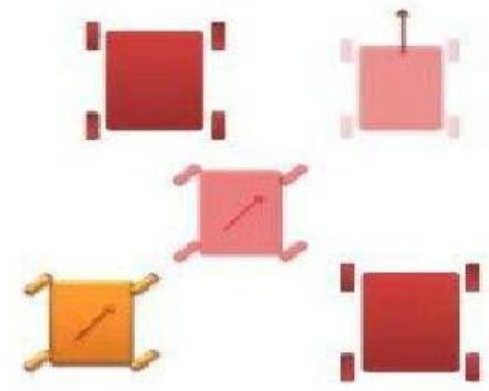

Fig 4: Lane Changing 


\section{THE CONCEPT INVOLVED}

Our Project consists a total of two Rack \& Pinions (one for front \& other for rear) and five Bevel Gears (two at the steering \& set of three in the mid region) as shown in the figure. Initially, as steering movement is given, say in the right direction. This drives the pinion in right direction and it engages the rack (connected to front wheels) towards the right thereby driving the front wheel to the right. First Bevel Gear is placed below the pinion to transfer the motion of the Pinion driven right. The second Bevel Gear is engaged vertically to the previous one and transfers the motion to the shaft in the opposite direction, i.e left. This shaft is further connected to the set of three Bevel Gears in which the first one attached to the shaft turns as same as the shaft (left), second one (engaged to the first) turns in the opposite direction (right) \& finally the third one (engaged to the second) turns opposite to the second one (left again). This leftward motion of the final Bevel Gear transmits leftward motion onto the pinion on the rear side, this engages the rack in the rear side towards left, thereby moving the rear wheels in the opposite direction of the front wheels. This depicts the turning mechanism of a vehicle at low speeds as explained in the Abstract of this paper.

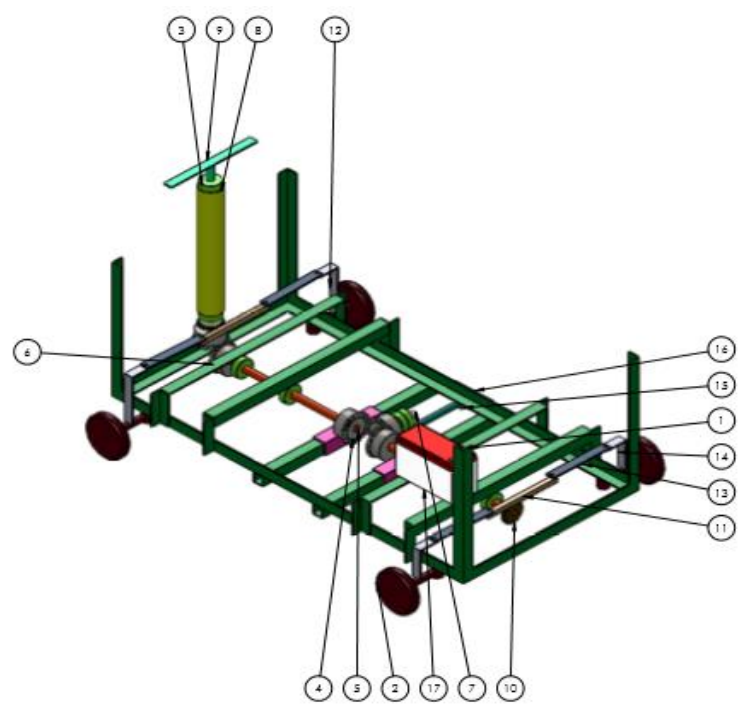

Fig. 5: Model Designed in Solid Works

\begin{tabular}{cc}
\hline SI No. & Parts Name \\
\hline 1 & Frame \\
2 & Wheel \\
3 & Bearing \\
4 & Bevel Gear Guide Tube \\
5 & Bevel Gear Guide Rod-1 \\
6 & Bevel Gear \\
7 & Bevel Gear Guide Rod-2 \\
8 & Steering Guide \\
9 & Steering \\
10 & Pinion \\
11 & Rack \\
12 & Wheel Angle-1 \\
13 & Wheel Plate \\
14 & Wheel Angle-2 \\
15 & Nut \\
16 & Sliding Bolt \\
\hline
\end{tabular}

IV. FINAL MODEL \& CALCULATIONS INVOLVED 


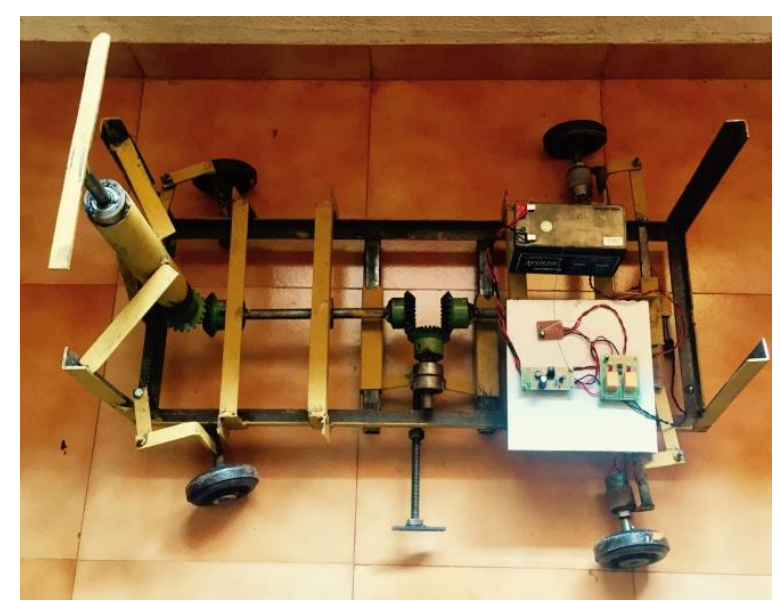

Fig. 6: Final Model with Remote Control

Beam strength of Bevel Gear

$\mathrm{W}_{\mathrm{t}}=\mathrm{S}_{\mathrm{d}} \mathrm{C}_{\mathrm{v}}$ Y.b.m $\left(1-\mathrm{b} / \mathrm{A}_{\mathrm{o}}\right)$

Above equation is known as Levis Equation

Material type: Steel

$\mathrm{D}_{\mathrm{p}}=50 \mathrm{~mm}$

$\mathrm{D}_{\mathrm{g}}=50 \mathrm{~mm}$

Module $=2 \mathrm{~mm}$

Face width, $\mathrm{b}=\mathrm{A}_{0} / 3 ; \mathrm{A}_{0}>30 \mathrm{~m} ; \mathrm{b}=7 \mathrm{~m}$ to $10 \mathrm{~m}$

$\mathrm{b}=17 \mathrm{~mm}$

Permissible Bending stress,

$\mathrm{S}_{\mathrm{D}}=\mathrm{S}_{\mathrm{u}} / 3=210 / 3=66.67 \mathrm{~N} / \mathrm{mm}^{2}$

Lewis Form Factor, $\mathrm{Y}=0.154-\left(0.912 / \mathrm{Z}_{\mathrm{V}}\right)$

$$
\mathrm{Z}_{\mathrm{V}}=\frac{\mathrm{Z}_{\mathrm{P}}}{\cos \alpha}=\frac{26}{\cos 45}=37
$$

Lewis Form Factor,

$$
\mathrm{Y}=0.154-(0.912 / 37)=0.129 \quad \mathrm{C}_{\mathrm{V}}=\frac{3}{3+\mathrm{V}}
$$

Where, $\mathrm{V}=$ Velocity $=\frac{\pi \mathrm{DN}}{60000}=\frac{\pi * 50 * 60}{60000}$

$$
\begin{aligned}
\mathrm{V} & =0.163 \mathrm{~m} / \mathrm{s} \\
\mathrm{Cv} & =\frac{3}{3+0.163}=0.94 \\
\mathrm{~A}_{\mathrm{O}} & =35.35 \mathrm{~mm}
\end{aligned}
$$

Beam strength of Bevel Gear,

$\mathrm{W}_{\mathrm{t}}=\mathrm{S}_{\mathrm{d}} \mathrm{C}_{\mathrm{v} .}$ Y.b.m (1- b/A $)$

$\mathrm{W}_{\mathrm{t}}=2 * 17 * 70 * 0.94 * 0.129(1-17 / 35.35)$

$\mathrm{W}_{\mathrm{t}}=449.43 \mathrm{~N}$

Therefore,

Beam Strength of Bevel Gear is 449.43 N

\section{Wear Strength of Bevel Gear}

$\mathrm{W}_{\mathrm{W}}=\frac{\text { K.be.D } . \mathrm{Q}}{\cos \alpha}$

$\mathrm{b}=$ Face width of Gear $=17 \mathrm{~mm}$

$\mathrm{Y}=$ Pitch angle $=45^{\circ}$

$\mathrm{Q}=$ Ratio Factor $=\frac{2 \mathrm{Z}_{\mathrm{vg}}}{\mathrm{Z}_{\mathrm{vp}}+\mathrm{Z}_{\mathrm{vg}}}$

$\mathrm{Q}=\frac{2 * 26}{26+26}=1$

$\mathrm{W}_{\mathrm{W}}=\frac{1 * 17 * 50 * 1}{\cos 45}=1202.08 \mathrm{~N}$

Therefore,

The wear strength of the Bevel gear is $1202.08 \mathrm{~N}$

\section{- $\quad$ Bearing}

The expression for dynamic load is given by,

$\mathrm{P}=\mathrm{XF}_{\mathrm{t}}+\mathrm{YF}_{\mathrm{a}}$ 
Where,

$\mathrm{P}=$ Equivalent dynamic Load $(\mathrm{N})$

$\mathrm{F}_{\mathrm{t}}=$ Radial Load

$\mathrm{F}_{\mathrm{a}}=$ Axial or Thrust Load $(\mathrm{N})$

$\mathrm{OD}=35 \mathrm{~mm}$

$\mathrm{ID}=15 \mathrm{~mm}$

$\mathrm{C}=$ Basic Dynamic Load $=6100 \mathrm{~N}$

$\mathrm{C}_{\mathrm{u}}=$ Basic Static Load $=3750 \mathrm{~N}$

$\mathrm{F}_{\mathrm{R}}=1000 \mathrm{~N}$ ( Assumption on basis weight of casing, body weight etc)

$\mathrm{F}_{\mathrm{A}}=2000 \mathrm{~N}$ ( Assumption on basis weigh of casing, body weight)

Comparing the ratio of radial and axial load to get the value of $\mathrm{X}$ and $\mathrm{Y}$

$\frac{\mathrm{F}_{\mathrm{a}}}{\mathrm{F}_{\mathrm{f}}}=\frac{1000}{2000}=0.5$

For the above equation e should be equal to 0.44

So now,

$\left(\mathrm{F}_{\mathrm{A}} / \mathrm{F}_{\mathrm{R}}\right)$ ie, $0.5>0.44$

Therefore,

$\mathrm{X}=0.56, \mathrm{Y}=1$

Thus,

$$
\begin{aligned}
\mathrm{P} & =0.56(2000)+1.49(1000) \\
& =1120+1400=2560 \mathrm{~N}
\end{aligned}
$$

Equivalent Dynamic Load Acting on the Bearing $=2560 \mathrm{~N}$

Dynamic Load Capacity of a bearing is given by,

$\mathrm{C}=\mathrm{P}\left(\mathrm{L}_{\mathrm{N}}\right)^{1 / 3}$

Where,

$\mathrm{L}_{\mathrm{N}}=$ Rated bearing life (in million revolution)

$6100=3750\left(\mathrm{~L}_{\mathrm{N}}\right)^{1 / 3}$

$\mathrm{L}_{\mathrm{N}}=13.53$ million revolutions

Therefore,

Rated bearing life is $\mathbf{1 3 . 5 3}$ million revolutions.

- $\quad$ Minimum Number Of Teeth To Avoid Interference

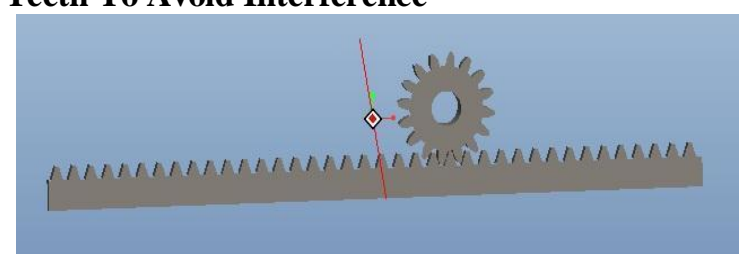

Fig. 7: Rack \& Pinion

For pinion,

$T_{p}=\frac{2 A_{w}}{G\left[\sqrt{1+\frac{1}{G}\left(\frac{1}{G}+2\right) \sin ^{2} \emptyset}-1\right]}$

$\mathrm{A}_{\mathrm{w}}=$ fraction by which the standard addendum for the wheel should be multiplied

$\mathrm{G}=$ Gear ratio or velocity ratio $=\mathrm{T}_{\mathrm{R}} / \mathrm{T}_{\mathrm{P}}$

$\mathrm{T}_{\mathrm{R}}=$ Number of teeth on rack $=44$

$\mathrm{T}_{\mathrm{PF}}=$ Number of teeth on front pinion $=26$

$\mathrm{T}_{\mathrm{PR}}=$ Number of teeth on rear pinion $=26$

$\phi=$ Pressure angle $=20^{\circ}$

Thus, substituting these values in the above equation,

$$
\begin{aligned}
\mathrm{T}_{\mathrm{PF}} & \left.=\frac{2 \times 1}{1.69\left[\sqrt{1+\frac{1}{1.69}\left(\frac{1}{1.69}+2\right) \sin ^{2} 20}-1\right.}\right] \\
\mathrm{T}_{\mathrm{PF}} & =13.76 \approx 14 \\
\mathrm{~T}_{\mathrm{PF}} & =\frac{2 \times 1}{1.69\left\{\sqrt{1+\frac{1}{1.69}\left(\frac{1}{1.69}+2\right) \sin ^{2} 20}-1\right]}
\end{aligned}
$$

$\mathrm{T}_{\mathrm{PF}}=13.76 \approx 14$

Therefore, Minimum number of teeth on front and rear pinion to avoid interference is $=14$ 


\section{- $\quad$ Linear Displacement Of Rack For One Rotation Of Pinion}

\section{For Front Rack}

Linear Displacement Of Rack For One Rotation Of Front Pinion ( LD1PF) LD1PF $=\pi \mathrm{mZ}_{\mathrm{P}}$

$=\pi \times 1.25 \times 26$

$\mathrm{LD} 1 \mathrm{PF}=102.101 \mathrm{~mm}$

Therefore, Linear displacement of rack for one rotation of front pinion is $=102.1 \mathrm{~mm}$

For Rear Rack

Linear Displacement Of Rack For One Rotation Of Rear Pinion ( LD1PR) LD1PR $=\pi m z_{\mathrm{P}}$

$=\pi \times 1.25 \times 26$

LD1PR $=102.101 \mathrm{~mm}$

Therefore, Linear displacement of rack for one rotation of rear pinion is $\mathbf{= 1 0 2 . 1} \mathbf{m m}$.

\section{RESULT \& ANALYSIS}

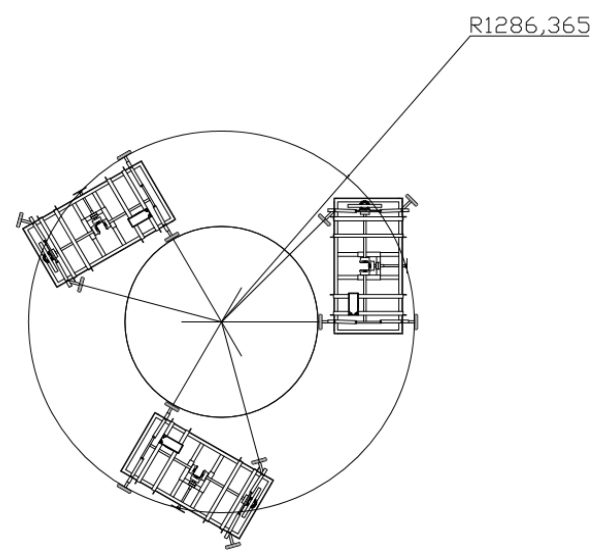

Fig. 8: Two Wheel Steering

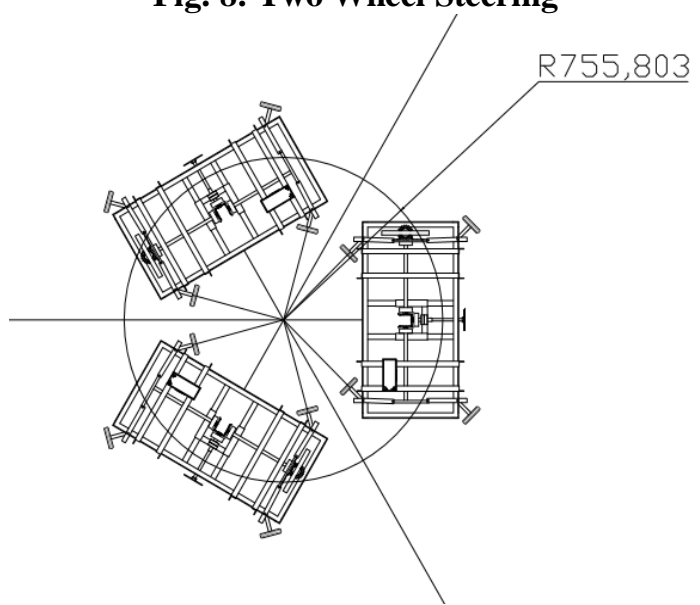

Fig. 9: Four-Wheel Steering

Thus, here we can see that two wheel turning circle radius of $1.286 \mathrm{~m}$ is reduced to $0.755 \mathrm{~m}$ of four wheel steering. Hence the achieved total reduction in turning circle radius of the vehicle is $62.9 \%$.

Thereby, a reasonable reduction in the circle radius is seen which could prove to be highly efficient in obtaining inphase \& Counter-phase rear steering with respect to front wheels.

\section{ADVANTAGES \& DISADVANTAGES}

\section{Advantages}
1. Easy maintenance
2. Mode change is easy
3. Implementation is easy
4. Better straight-line stability
5. Better high speed maneuvers 
6. Improved steering response

7. Reduces the snaking effect

8. Removes the use of traction control

\section{Disadvantages}

1. It will increase the total cost of the vehicle almost by 25000 on mass production

2. Suspension in rear wheels demands considerable changes for proper working of the vehicle with varying load.

\section{CONCLUSION}

As per the focus of the project we have created an innovative 4 wheel active steering mechanism which is feasible to manufacture, easy to install and highly efficient in achieving in-phase and counter-phase rear steering with respect to the front wheels using DRRC. This system assists in high speed lane changing and better cornering. It combats the problems faced in sharp turning. It reduces the turning circle radius of the car and gives better maneuverability and control while driving at high speeds, thus attaining neutral steering. Moreover components used in this system are easy to manufacture, material used is feasible, reliable and easily available in market. The system assembly is easy to install and light in weight and can be implemented in all sections of cars efficiently.

\section{FUTURE SCOPE}

1. Computer-controlled Quadra-steer is possible and it can be switched on and off and has an effective trailer towing mode.

2. Computer determines how much and in which direction the rear wheels should move, and whether the rear wheels should turn the same direction as the front wheels or in the opposite direction.

3. It can be used in all common vehicles.

\section{REFERENCES}

[1] K. Lohith, Dr. S. R. Shankapal, \& Mr. H. Monish Gowda "Development of Four Wheel Steering System for a Car," SAS Tech Journal, vol. 12, pg. 90-97, Issue 1, April 2013

[2] Honda official website http://automobiles.honda.com/civic-sedan/specifications.aspx

[3] Dr. Kirpal Singh “Automobile Engineering” Standard Publishers Distributors, vol. 1, 12th Edition, 2011.

[4] V. B. Bhandari “Design of Machine Elements” McGraw Hill Education India Pvt. Ltd., vol. 3, 11th Edition, 2013.

[5] K.Balaveera Reddy - Design Data Handbook - CBS

[6] H.G.Patil - Machine Design Data Handbook - Sri Shashi Prakashan

[7] Design and stimulation of four wheel steering system (International Journal of Engineering \& Innovative Technology).

\section{BIOGRAPHIES}

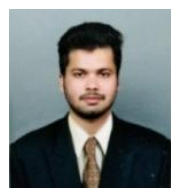

Mr. K J Yogesh, Dept. of Mechanical Engineering Jain College of Engineering, Belagavi

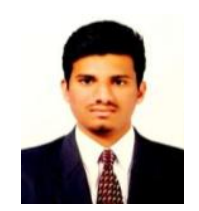

Mr. Mohd Rehan Desai, Dept. of Mechanical Engineering Jain College of Engineering, Belagavi

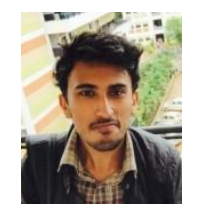

Mr. Mohammed Ali Fazal Shaikh, Dept. of Mechanical Engineering, Jain College of Engineering, Belagavi

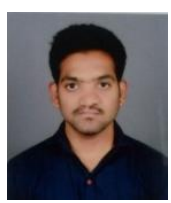

Mr. Praveen Gasthi, Dept. of Mechanical Engineering Jain College of Engineering Belagavi 